\title{
BM Global Heath Global health is dead; long live global health! Critiques of the field and its future
}

\author{
Martha Lincoln
}

To cite: Lincoln M. Global health is dead; long live global health! Critiques of the field and its future. BMJ Global Health 2021;6:e006648. doi:10.1136/ bmjgh-2021-006648

Handling editor Seye Abimbola

Received 17 June 2021

Accepted 23 June 2021

\section{Check for updates}

C) Author(s) (or their employer(s)) 2021. Re-use permitted under CC BY-NC. No commercial re-use. See rights and permissions. Published by BMJ.

Anthropology, San Francisco State University, San Francisco, California, USA

Correspondence to

Dr Martha Lincoln;

mlincoln@sfsu.edu
Suppose we accept the intriguing premise that 'health is politics by other means', as the sociologist Alondra Nelson has argued. What does this mean for global health?

We might first extrapolate along familiar lines: global health outcomes are conditioned by the dynamics of international realpolitiktrade, foreign policy, and armed conflict—and as such, the task of global health professionals is to study and mitigate these impacts. But less comfortably, Nelson's provocative axiom suggests that the field of global health itself is a site of political manoeuvring, interinstitutional struggles, ideological agendas and attempted elite capture. In this increasingly widely shared view, the mechanisms for delivering medical services and resources to the Global South are part of a global apparatus of political and economic domination and not a hedge against it.

Global health professionals thus inhabit a contradiction. Though it is incumbent on the field to articulate aspirational agendas, the project of global health has also represented a venue for some of the world's most powerful political and economic institutions to advance their interests. Hence, the discipline has found itself on uncertain footing in recent years, struggling with both its history and its future. At the present moment, perhaps no one is better positioned to call attention to these contradictions than critically minded practitioners active within the organisations that plan global health programmes and deliver their services.

Four recently published volumes illustrate the importance of critiques articulated within and against global health. The authorseach of whom is trained as an anthropologist as well as a global health practitioner-base their assessments on case studies in the Global South: respectively, the scale-up of HIV/AIDS treatment in efforts to end the global epidemic, with a focus on the Caribbean nation of
Grenada $^{1}$; the privatisation of medical services in Tajikistan, a republic of the former Soviet Union $^{2}$; and the international humanitarian response to Ebola outbreaks in West Africa in 2013-2016. ${ }^{34}$

From these distinct experiences, each author identifies a suite of troubling dynamics in global health institutions and practices-from the withholding of desperately needed clinical resources in crisis settings to the removal of assistance from public health interventions that fail to meet programme targets to the planned commercialisation of medicine amid economic collapse. Their accounts call for substantive reconceptualisation of the political, ideological and material foundations of global health interventions. And though the works disagree about the original causes of the problems they describe, they ultimately deliver quite similar assessments of the political economy of global health: each implicates the influence of austerity principles, showing manufactured scarcity to be a-if not the-root cause of systemic dysfunction.

Facing divestment by some of the largest donors to global health-including the USA under the Trump administration-health agencies at all levels have encountered increasing pressure to deliver evidence of goals attained and investments well spent. On its face, the push to rationalise global health with data appears utopian: more data should mean more accountability, permitting more precisely targeted interventions. In The Uncounted: Politics of Data in Global Health, anthropologist and global health professional Sara Davis troubles this view of data as panacea, revealing how some uses of data can retrench existing injustices.

As Davis suggests, over a quite brief and recent period, global health has become inconceivable without metrics, models and indicators. These tools, with the concomitant logic of 'cost-effectiveness', have also moved to the centre of global HIV/AIDS response, 

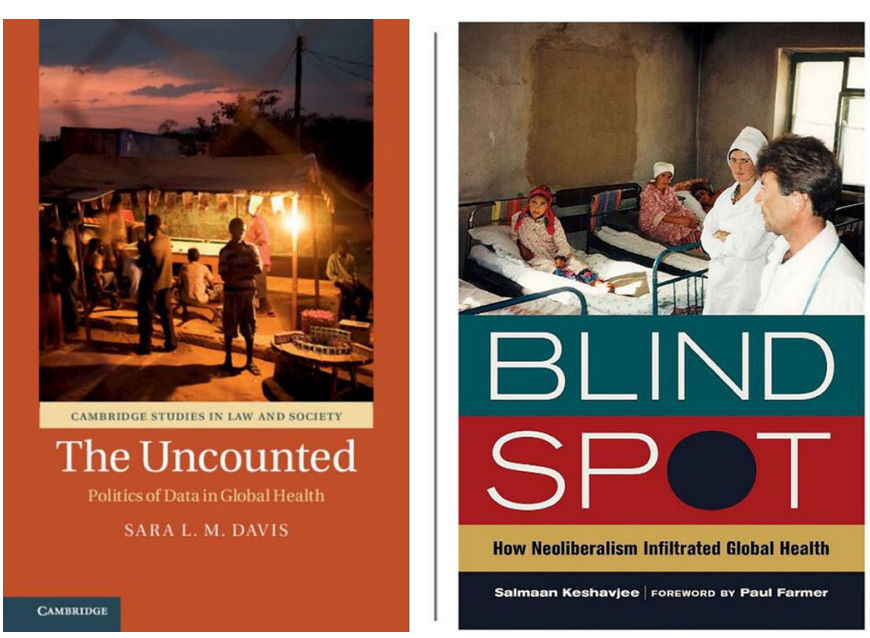

including the 'Fast-Track approach' that Davis examines over the book's chapters. Introduced by the Joint United Nations Programme on HIV/AIDS (UNAIDS) in 2016, this ambitious strategy to 'end AIDS' worldwide by 2030 relied on scaling up testing and antiretroviral therapy to meet predetermined targets. Since it was introduced, this laudable effort to eradicate HIV/AIDS-also legible as a means of containing future costs and staving off 'donor fatigue'-has driven large-scale shifts in priorities for resource expenditure.

While Davis does not question that the initiative of eradicating HIV is being carried out in good faith, her assessment suggests how institutional models of the pandemic may be shaped by a streetlight effect- the tendency to search for something where the light is brightest. In HIV epidemiology, the light is typically brightest in settings where HIV prevalence is high and where at-risk populations are not stigmatised and criminalised. In settings where 'key populations' like commercial sex workers and men who have sex with men are marginalised, they are less likely to be visible to the systems that compile and disseminate data. When countrylevel statistics fail to include key populations, funders may withdraw resources, due to the mistaken impression that there is no more work to be done. In Grenada, where Davis focuses much of The Uncounted, the Global Fund to Fight AIDS, Tuberculosis and Malaria was preparing to transition out-potentially permanently-and threatened to leave numerically small but economically and socially vulnerable populations without support. Davis observed the process of developing new estimates of key populations in Grenada to demonstrate the need for continued funds.

At base, these decisions are driven by diminishing resources. As Rico Gustav, an Indonesian HIV/AIDS activist, stated to Davis, 'We're sabotaging ourselves with these zero-sum conversations. Of course, the resources are limited. But (...) as a global community, we're not having a conversation about how to increase the overall pie. We actually need to have that conversation really badly' (Davis, p. 172). ${ }^{1}$ In a field of shrinking global health investment, rights holders can 'become either winners and losers'
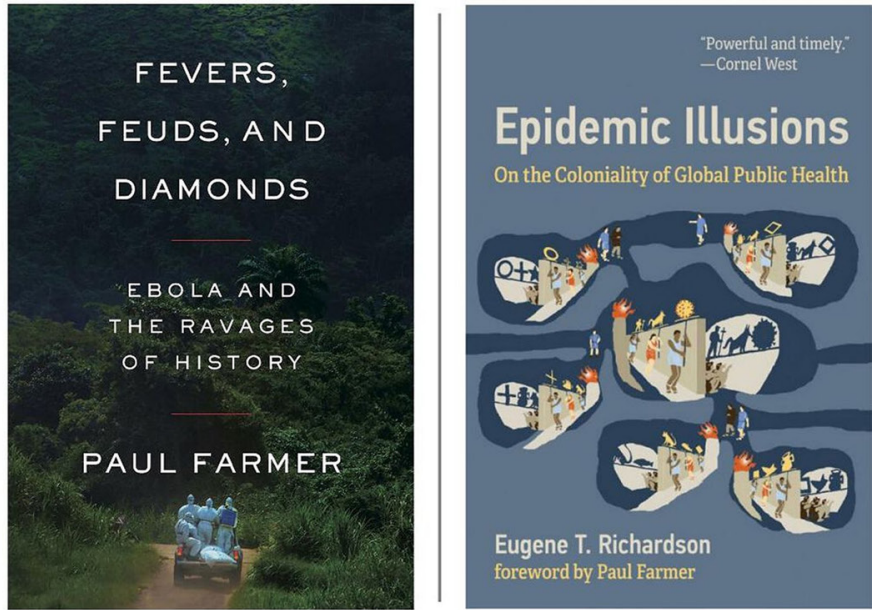

(Davis, p. 113) ${ }^{1}$; quantification can further routinise ethically impossible choices.

A different type of selective vision is profiled in Salmaan Keshavjee's Blind Spot: How Neoliberalism Infiltrated Global Health. As a doctoral student in the mid-1990s, Keshavjee conducted ethnographic fieldwork in Tajikistan, a Central Asian republic whose social safety net collapsed with the fall of the Soviet Union. A subsequent civil war compounded the dire situation of Tajikistan's post-Soviet public health. (As Keshavjee's elegantly related history of the region reveals, living standards were higher under the Soviet system than after its collapse, despite the non-trivial difficulties of the socialist period.) An international development non-governmental organisation (NGO), the Aga Khan Foundation (AKF), stepped in to remedy the 'disappearance of the state' (Keshavjee, p. 53). ${ }^{2}$ Working in the AKF's health department, Keshavjee studied the population's ability to access medicine and health services. Thus, he was able to observe the effects of a brutal 'transition' on collective welfare and living standards: chronic paediatric stunting, infant deaths caused by diarrhoeal disease and people reduced to 'medieval modes of transportation' (Keshavjee, p. 52). ${ }^{2}$

The focus of Keshavjee's observations is the establishment of a 'revolving drug fund' to subsidise the posttransition healthcare system. This model, which had been endorsed under the Bamako Initiative of the late 1980s, was intended to generate funds with the introduction of fees for pharmaceutical drugs: a donor would contribute an initial grant to purchase a stock of drugs, the costs of the drugs would be marked up, and the proceeds from patients' drug purchases would be used to purchase a new supply. But what this meant in practice was that a population experiencing unprecedented levels of despair would now be asked to pay out of pocket for essential drugs. One patient whom Keshavjee interviewed about the prospect of fees for pharmaceuticals stated the following:

That is impossible. It is destruction. It is a way to catastrophe. My family and I, and the whole of Badakhshan's 
population, will not be able to use the treatment. We'll have to forget the word medicine (Keshavjee, p. 60). ${ }^{2}$

Yet this unpromising intervention was not a misstep. As Keshavjee demonstrates, the project was implemented specifically because it aligned with the core ideals of neoliberalism: an influential economic theory that has, since the end of World War II, reshaped public policy at all scales of government. Neoliberal policies emphasise the use of market mechanisms in favour of state entitlementsincluding for such vital social services such as preventive health. Through a concerted effort by its exponents, neoliberal ideology was introduced into international political circles over the course of the Cold War, with NGOs coming to represent a favoured means of displacing the influence of national governments.

As Keshavjee argues, it is diagnostic of neoliberalism's pervading influence that a conscientious and impeccably run development agency like the AKF would-for exampleprovide a loan instead of a grant to a Badakhshan dentist who hoped to provide free services to his poorest patients. Thus, the author urges his audience to 'save their disapprobation for (...) the discursive landscape that has led dogma to replace data' in global healthcare delivery (Keshavjee, $\mathrm{p}$. 17)..$^{2}$ The 'global health failure' he observed in Tajikistan took place in tandem with 'neoliberal success' (Keshavjee, p111). ${ }^{2}$

Where Keshavjee suggests that the blind spot in global health originates with the ascendance of neoclassical economics in policy circles worldwide, Eugene Richardson presents a critique much closer to home in Epidemic Illusions: On the Coloniality of Global Public Health. While Richardson attributes the Global South's disparate burden of ill health to what he terms coloniality-a 'matrix of power relations' (Richardson, p. 3) ${ }^{3}$ affecting formerly colonised places, shaping life and life chances-he does not cast public health science as an innocent bystander. Quite the contrary: Richardson asserts that the enterprise of global health has apprehended, defined and addressed global health problems in ways that essentially ensure that they will not be meaningfully resolved. In this view, global health praxis is inherently-if perhaps inadvertently-complicit with the interests of powerful institutions and nations, functioning to corroborate their perspectives and reify them as common sense.

Some readers may struggle to accept these contentions because they contradict their own good-faith efforts to intervene responsibly. Indeed, Richardson is no stranger to such efforts himself, having worked in programmes to manage and control infectious disease in a host of international settings. Much of Epidemic Illusions addresses the Ebola outbreaks in Sierra Leone, Liberia and Guinea from 2013 to 2016, where Richardson worked with Partners In Health (PIH) to care for the critically ill. Richardson's critique is thus that of an insider-albeit one whose intellectual commitments extend well past the 'hard' sciences, as the highly experimental form of his book suggests. He reports on some of the grimmest and most dismaying moral errors of the humanitarian response: for example, the mandate that patients in the Ebola Treatment Units of some international aid agencies could not receive intravenous rehydration, even if they were unable to swallow oral rehydration solution without vomiting it back up. Here, Richardson compares these protocols with colonial practices of withholding medical resources, sequestering sick patients and constructing an abusively post hoc moral architecture to justify these failures of care.

Richardson is particularly sceptical about the potential of epidemiology to deliver an adequately radical assessment of what he understands to be the most significant drivers of global health inequity. Like Davis, Richardson sees quantitative data as a culturally potent means of mystifying what are essentially political problems and rendering them into 'numeric bits amenable to mathematical manipulation' (Richardson, p 48) ${ }^{3}$; he terms epidemiology a 'mathematised ideological system' (Richardson, p. 96). ${ }^{3}$ In the experience of the West African Ebola outbreaks, this meant that epidemiological models were afforded a great deal of influence despite delivering incomplete and sometimes quite flawed and misleading analysis.

For example, Richardson shows how the media-friendly term 'superspreader' - and the idea that 'superspreaders' were driving the Ebola epidemics - gained undue explanatory power, while more complex inputs to disease risk were bracketed outside the analytical frame. The idea of superspreading ultimately also fuelled discourses that blamed victims and their allegedly 'cultural' practices-which were, as Richardson convincingly demonstrates, thoroughly rational and pedestrian responses to situations of social upheaval amid extreme and long-standing dispossession. Richardson contends that the true superspreaders of Ebola are the predatory actors who have historically impoverished and destabilised the region. This view is informed by the interviews he conducted with Ebola virus disease survivors, who likewise implicated 'corrupt national governments, foreign corporations (...) and the legacy of the Maafa (African holocaust)' (Richardson, p. 98) ${ }^{3}$ in setting the stage for a public health disaster.

Epidemic Illusions can be constructively read together with physician-anthropologist Paul Farmer's Fevers, Feuds, and Diamonds, not least because the two scholar-clinicians worked side by side to establish the presence of PIH and assist patients in Sierra Leone during the Ebola epidemics. Where Richardson's analysis offers an especially focused reading of the ideological dimensions of Ebola in the discourse of global health research and praxis, Farmer's volume supplies an expansive history of the upstream variables that smoothed the path for Ebola to become West Africa's 'storied perfect storm' (Farmer, p. 358), ${ }^{4}$ as the global health community often called it. However, Farmer rejects the exculpatory framing of a 'perfect storm', asking instead: how could a world region boasting such abundant natural wealth have become 'a public health desert ... and a clinical desert' (Farmer, p. 28), , subject to the 'therapeutic nihilism' of some of the world's most respected humanitarian aid agencies? 
Much of Fevers, Feuds, and Diamonds thus reads as a work of forensic detection, though one with a very long reach. Farmer identifies multiple generations of intellectual and material authors, living and dead, of anthropogenic crisis in West African public health and health systems. Pursuing root causes in vivid specific detail, he establishes that the clinical desert was a contingent outcome-neither a foregone conclusion nor an accident-and that its contours were profoundly influenced by successive foreign-led regimes of slaving, colonialism, resource extraction and structural adjustment. Retrieving, as Farmer writes, 'more than a little history from the dustbin' (Farmer, p. 45), the work contextualises the emergence and spread of Ebola in the region's long-standing situation as a node in global networks of exploitation, extraction and violence.

As Farmer acquaints the reader with the political history of places and populations that are too often depicted with alienating and exoticising generalisations, he also establishes how poorly these schemata mesh with the true historical particulars. Farmer debunks myths at every scale of analysis: from questionably premised accounts of Ebola's 'patient zero' to speculative discourse about the 'ethnic' or 'tribal' roots of African civil conflict. Such naïve or cynical theories proliferated in scholarly journals as well as global media during the outbreaks, attributing the transmission of disease to those least empowered to protect themselves.

Though this volume covers an enormous amount of terrain-an Odyssey or Iliad in global public health-its core argument is simple. Farmer submits that responsibly tendered medical care and a functioning healthcare system would have prevented the transmission of Ebola by inspiring public trust and shifting caregiving into professional settings-and that political economic regimes that operate by limiting and withholding care thus are vectors not only of violence but also of contagion. Farmer concurs with Richardson in noting that global response to Ebola recapitulated a long-established pattern of 'control over care': treating people as objects of medical control rather than subjects deserving of resources, compassion, and dignity.

Farmer's project thus works against the tendency of global health agencies (and others) to see an emergency in narrow tunnel vision. Fevers, Feuds, and Diamonds refuses the overheated, spectacularising tenor of much popular (and scientific) writing about Ebola, and Farmer's patient historicisation of the deep roots of public health in West Africa makes an argument in its own right: for global health to equip itself with explanatory models and situational appraisals that are humanistic, critically historicised, and focused on upstream material causes.

These works present potent critiques of neoliberalism, austerity, and coloniality and their ill effects on health and human rights worldwide. Taken together, they show global health to be, at best, an insufficient bulwark against the enormous amount of symbolic and material violence that has been levelled at the Global South over the longue durée and into the present. While this insight is disturbing, the authors also offer paths forward.
As Keshavjee comments, a great deal of harm has proceeded from former Prime Minister Margaret Thatcher's claim that 'there is no alternative' to a political economic model that mandates a dystopian race to the bottom. Of course, there have always been alternatives, and we are now entering what may be an opportune moment to bring them into public conversation. Several of the authors also reference an infamous quote by Chicago School economist Milton Friedman (while noting how the global ascendancy of his views has authored a great deal of human suffering). As Friedman wrote, 'Only a crisis-actual or perceivedproduces real change. When that crisis occurs, the actions that are taken depend on the ideas that are lying around. That, I believe, is our basic function: to develop alternatives to existing policies, to keep them alive and available until the politically impossible becomes the politically inevitable'.

Written during a period of neoliberal supremacy, enforced scarcity, and pessimistic moral compromises-a good share of which can, again, be laid at the feet of Friedman et althese works have kept critical ideas about the potential of global health alive and available, and their authors call for nothing short of a revolution in the field. This research should be widely read by global health agency heads, programme managers, practitioners and scholars as a step towards continuing to transform and revolutionise established ways of seeing. The crisis of the COVID-19 pandemic will—even if only briefly—give credence to arguments for much more meaningful funding commitments to the 'staff, stuff, space and systems' of healthcare around the world. In a window of potentially fleeting opportunity, practitioners should seize on these critiques and set radical agendas for a new global health.

\section{Twitter Martha Lincoln @heavyredaction}

Funding The authors have not declared a specific grant for this research from any funding agency in the public, commercial or not-for-profit sectors.

Competing interests The author served as editor for Eugene Richardson's monograph Epidemic Illusions.

Patient consent for publication Not required.

Provenance and peer review Not commissioned; internally peer reviewed. Data availability statement There are no data in this work.

Open access This is an open access article distributed in accordance with the Creative Commons Attribution Non Commercial (CC BY-NC 4.0) license, which permits others to distribute, remix, adapt, build upon this work non-commercially, and license their derivative works on different terms, provided the original work is properly cited, appropriate credit is given, any changes made indicated, and the use is non-commercial. See: http://creativecommons.org/licenses/by-nc/4.0/.

\section{REFERENCES}

1 Davis SL. The uncounted: politics of data in global health. New York: Cambridge University Press, 2020: $301 \mathrm{p}$

2 Keshavjee S. Blind spot: how neoliberalism infiltrated global health. Oakland, CA: University of California Press, 2014: 240 p.

3 Richardson E. Epidemic illusions: on the coloniality of global health. Cambridge, MA: MIT Press, 2020: 193 p.

4 Farmer P. Fevers, feuds, and diamonds: Ebola and the ravages of history. New York: Farrar, Straus and Giroux, 2020: 653 p. 